\title{
A trial study on a mixture of Acridine and Giemsa stains and modified Quantitative Buffy Coat for detection of malaria parasites
}

\author{
Abdulazeez Aderemi ABUBAKAR ${ }^{1 *}$, Mr. Ismail Adedapo ABDULRAHEEM ${ }^{2}$ and \\ Sulaiman Adebayo NASSAR ${ }^{3}$ \\ ${ }^{I}$ Department of Medical Laboratory Science University of Medical Sciences, Ondo-City, Nigeria. \\ ${ }^{2}$ Department of Medical Laboratory Science, Kwara State University Malete- Ilorin, Nigeria. \\ ${ }^{3}$ Department of Biomedical Sciences, College of Health Siences LAUTECH, Osogbo, Nigeria. \\ *Corresponding author; E-mail: aabubakar@unimed.edu.ng; Tel: +2348068039485.
}

\begin{abstract}
Microscopy after Geimsa staining remains the gold standard technique for detection of malaria parasites while Acridine is a common fluorescent stain that enhances the visibility of parasites. Combination of both stains could further enhance the performance of microscopy technique. The aim of this study was to investigate the efficacy of staining with mixture of Acridine and Giemsa and modified Quantitative Buffy Coat technique in detection of plasmodium parasites. Five hundred and seventy (570) volunteered students attending the Kwara State University Health Center Malete with history malaria fever and tested positive for malaria parasite were re-examined with the two methods being investigated. Two millilitres of the blood sample from each subject was collected into EDTA container and mixed properly. Thick smears were made in duplicate from each sample and properly labeled, stained by Giemsa and Acridine-Giemsa techniques and examined under x100 objective of the microscope while the remaining blood samples were also tested by Modified QBC. The study assessed the Sensitivity, Specificity, Positive Predictive Value and Negative Predictive Value of both techniques with respect to Giemsa microscopy as a gold standard. Findings from the investigation showed that modified QBC and Acredine-Giemsa techniques recorded sensitivity of $100 \%$ and $99.7 \%$ respectively. Concentrated Acridine-Giemsa stain recorded higher specificity (90.7\%) than modified QBC with $82.5 \%$ using Geimsa staining as a gold standard. The Positive Predictive Value (PPV) for Modified QBC and AcredineGiemsa techniques were $96.8 \%$ and $96.5 \%$ respectively whereas the Negative Predictive Value (NPV) for both methods were $100 \%$ and $98.7 \%$ respectively. In conclusion, the finding depicts a keen competition between Acridine-Giemsa staining method and Modified QBC technique for detection of malaria parasites and there was no significant difference in the efficacy of both methods with respect to detection of malaria parasite. (C) 2019 International Formulae Group. All rights reserved
\end{abstract}

Keywords: Acridine-Giemsa, Modified QBC, Efficacy, Microscopy, Gold standard.

\section{INTRODUCTION}

Malaria is a life-threatening infection caused by Plasmodium protozoa transmitted by a female Anopheles mosquito (Caraballo, 2014). Plasmodium falciparum infection can cause a high mortality if untreated, but it has an excellent prognosis if diagnosed early and treated appropriately (Tilley et al., 2011Gera and Chauhan, 2015). The disease is the most important mosquito borne parasitic infection of man caused by parasites of the genus Plasmodium and they are leading cause of 
morbidity and mortality worldwide (Abeku, 2007; Mlambo and Kumar, 2008; Meade and Emch, 2010; Collins, 2012). Four species of malaria parasite infect human beings; they are Plasmodium falciparum Plasmodium vivax, Plasmodium ovale and Plasmodium malariae (Baird, 2009; Barry and Reeder, 2012; Arnott and Baird, 2013; Chakrabortya et al., 2015).

Malaria is prevalent in tropical and subtropical regions because of significant amount of rainfall, warm temperature, high humidity and stagnant water in which the larvae mature providing mosquitoes ideal environment needed for continuous breeding (Gera and Chauhan, 2015). In Africa, official report indicated that annual deaths emanating from malaria is about 3 million cases especially among children under five years of age (Ngbolua et al., 2011; Sagare et al., 2012). Considering the emerging resistance of Plasmodium falciparium strains against most antimalarial drugs including the most recent Athemisinine-based Combination Therapies (Mfopa et al., 2017), early diagnosis of the infection is essential for effective treatment and control (Gething, et al., 2010). Microscopy remains gold standard in malaria diagnosis even though rapid diagnostic tests are increasingly used (Khan and Anwar, 2004; Bhandari et al., 2008). Microscopy is advantageous because it provides a quantitative assessment of peripheral blood parasitemia and stages of the parasite as well as information on other heamo-parasites (Ameri, 2014; Sathpathi et al., 2014; Manguin et al., 2017).

Diagnosis of malaria based on microscopy has central importance for species differentiation, parasitic quantification and management of severe disease (Owusu-Ofori, Parry and Bates, 2010; Chakrabortya et al., 2015). Microscopy requires technical expertise of the microscopists and it is time consuming (Bartoloni and Zammarchi, 2012). To overcome the limitations of conventional microscopy many alternative rapid diagnostic methods devoid of dependence on microscope such as rapid immunochromatographic assays and the sensitive molecular techniques like DNA hybridization and polymerase chain reaction have been introduced (Shapiro and Mandy, 2007; Gera and Chauhan, 2015).
These methods also have their own limitations and should be used as complementary methods to conventional microscopy (WHO, 2016). Management of malaria requires rapid and accurate detection of presence of parasite in human blood (Mehlhorn, 2008; OlupotOlupot and Maitland, 2013; Abba et al., 2014).

The aim of this study was to investigate the efficacy of staining with mixture of Acridine and Giemsa stains and modified Quantitative Buffy Coat technique in identification of malarial parasites using conventional microscopy with Giemsa staining method as a gold standard.

\section{MATERIALS AND METHODS \\ Sample collection}

Five hundred and seventy (570) volunteered students attending Health Center of Kwara State University Malete, Nigeria with history of malaria fever and tested positive for malaria parasite were re-examined with Acridine-Giemsa staining and modified QBC methods. Two milliliters of the blood sample from each subject was collected into EDTA container and mixed properly.

Prior to commencement of the study, ethical approval was sought and obtained from Ethical Review Committee of School of Basic Medical Sciences of the university (Reference number KWA/SBMS/EACC/134). Also, approval was obtained from the Director of Kwara State University Health Center to enroll the subjects attending the center for the study. Processing and analysis of the specimens were conducted in the Multipurpose Laboratory of Department of Medical Laboratory Science of the University.

\section{Laboratory processing of blood samples}

Thick smears were made in duplicates from each sample and properly labeled. The first smear was air dried and stained with Giemsa according to the procedure described by WHO (2010) while the second was stained by Acridine-Giemsa staining technique and examined under $\mathrm{x} 100$ objective of the microscope. The Acridine-Giemsa orange stain was prepared in ratio $2: 3(40 \%$ to $60 \%)$ in which $40 \mathrm{ml}$ of concentrated Acridine Orange was mixed with $60 \mathrm{ml}$ of concentrated 
Giemsa. The mixture of both stains was flooded on each slide and left for 10 minutes on the bench at room temperature before rinsing with buffered distilled water with $\mathrm{PH}$ 6.8. At least 200 fields of the microscope were examined under x100 objective lens before reporting a sample to be malaria parasite negative. Thick smear was used for the identification of the parasite while thin smear was used for the speciation of the parasite.

\section{Modified Quantitative Buffy Coat Technique}

In modified QBC technique, ordinary thin glass capillary tube was employed instead of the conventional Becton Dickson thick capillary tube. The alternative tube was coated with EDTA and heparin at the fill end and with Acridine Orange and potassium oxalate at the other end. About $60 \mu \mathrm{l}$ of blood sample, was put in the tube by capillary action. The tubes were rotated for 10 seconds in order to dissolve the contained residues in the blood. The tubes were then centrifuged at $10,000 \mathrm{rpm}$ for 5 minutes. The area surrounding the float just beneath the buffy coat was examined under X 100 objective of the microscope. Malaria parasites stained green and orange under the blue-violet light. The entire circumference of each tube was examined systematically while moving away from the buffy coat until parasites were detected or otherwise

\section{Statistical Analyses}

Data obtained from the study were input and analyzed with Statistical Package for Social Sciences software of computer (Version 17 SPSS Inc, USA). Student's Ttest was used to assess the efficacy of modified QBC and combined AcridineGiemsa staining techniques for detection of malaria parasites in blood samples using Giemsa method as a gold standard. The test for significance level was based on a $\mathrm{P}$ value less than 0.05. Different indices of efficacy were calculated from the data obtained from both techniques being investigated with respect to Giemsa staining as reference standard while appropriate formulae documented by Anagu et al. (2015) were applied:
Percentage positivity $=$ TP/Total $\times 100 \%$

Percentage negativity $=$ TN/Total $\times 100 \%$

Sensitivity $=\mathrm{TP} /(\mathrm{TP}+\mathrm{FN}) \times 100 \%$

Specificity $=\mathrm{TN} /(\mathrm{TN}+\mathrm{FP}) \times 100 \%$

Positive Predictive Value $=\mathrm{TP} /(\mathrm{TP}+\mathrm{FP}) \times$ $100 \%$

\section{RESULTS}

Positivity rate of Modified QBC and concentrated Acridine-Giemsa staining for malaria parasite detection in human samples using Giemsa microscopy as gold standard is as shown in Figure 1. Out of the 570 samples tested, 466(81.7\%) were positive by Giemsa staining, 492(86.3\%) by Modified QBC and 494(86.7\%) by Acridine-Giemsa staining. Of the positive samples, Giemsa staining failed to detect $26(4.6 \%)$ positive samples which were hitherto positive with Modified QBC and 24(4.2\%) samples detected by AcridineGiemsa staining method.

Table 1 shows the accuracy of Acridine-Giemsa staining and modified QBC techniques in identification of Plasmodium parasite using Giemsa staining method as a gold standard. Out of 570 samples examined with Acridine-Giemsa staining method; 492, 78,18 and 1 samples were recorded as total positive, total negative, false positive and false negative respectively while 494, 76, 16 and 0 were respectively recorded when modified quantitative buffy coat technique was employed

Efficacy of Modified QBC and Acridine-Giemsa staining on detection of malarial parasites in human sample using Giemsa staining technique as Gold Standard is as depicted in Table 2. The sensitivity, specificity, Positive Predictive Value (PPV) and Negative Predictive Value (NPV) for Modified QBC were 100\%, 82.5\%, 96.82\% and $100 \%$ respectively with respect to Giemsa staining. Assessing the efficacy of AcridineGiemsa staining method, $99.7 \%$ was recorded for sensitivity whereas specificity, Positive Predictive Value and Negative Predictive Value respectively recorded $90.7 \%, 96.5 \%$ and $98.7 \%$. Statistically, efficacy indices of Acridine-Giemsa staining and Modified QBC techniques depicted insignificant difference $(\mathrm{P}$ value $=0.9623 ; \mathrm{P}>0.05)$ when analyzed with Student's T-test at 95\% confidence level. 


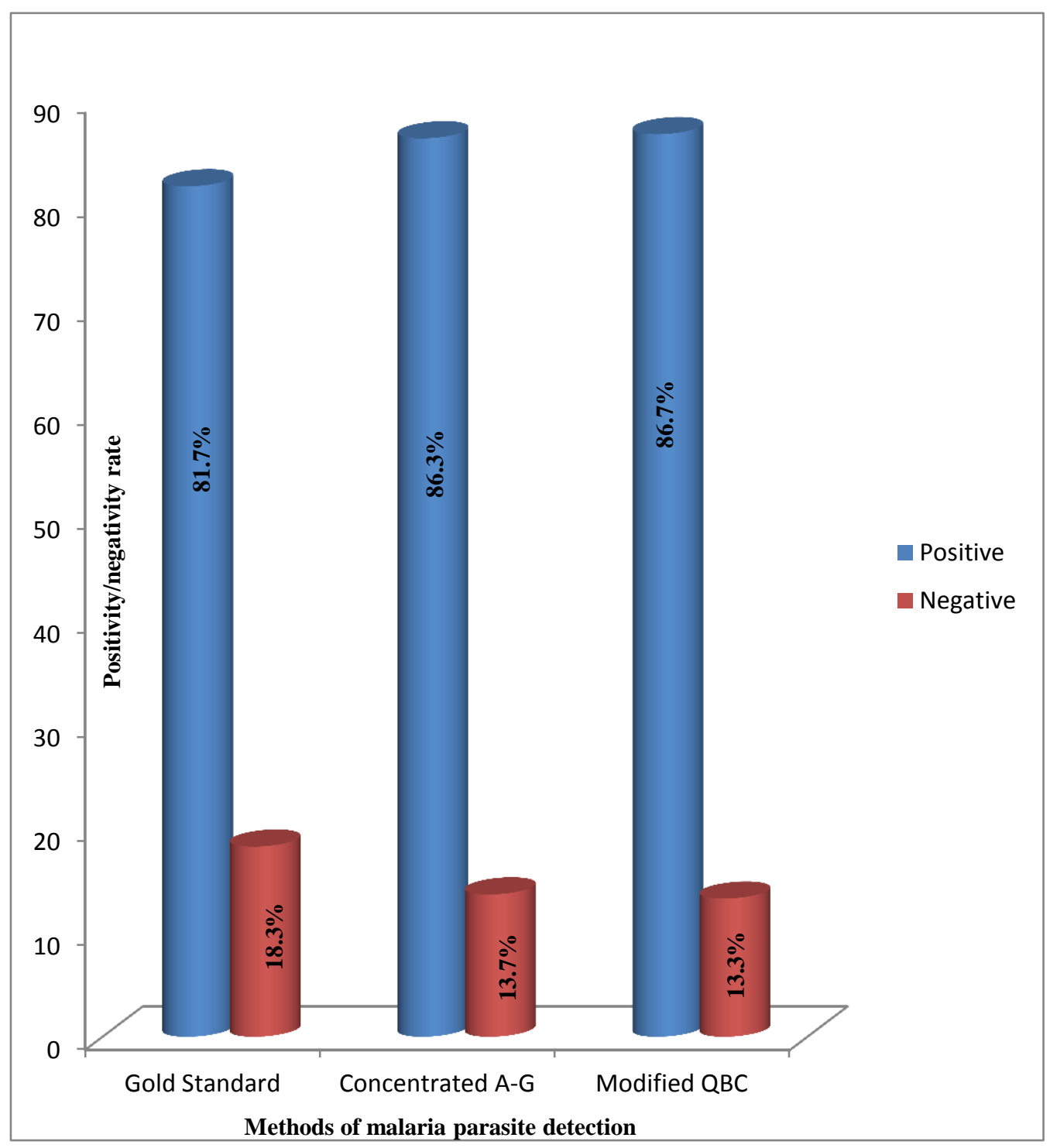

Figure 1: Positivity rate of combined Acridine-Giemsa staining and modified QBC techniques for malaria parasite detection using Giemsa staining as a gold standard.

Table 1: Accuracy of Plasmodium parasite identification by Acridine-Giemsa staining and modified QBC techniques using Giemsa staining method as a gold standard.

\begin{tabular}{lccccc}
\hline & & \multicolumn{3}{c}{ Number examined (n) $=570$} \\
\cline { 4 - 6 } $\begin{array}{l}\text { Method } \\
\text { Examined }\end{array}$ & $\begin{array}{c}\text { Number } \\
\text { Positive (TP) }\end{array}$ & $\begin{array}{c}\text { Total } \\
\text { Negative (TN) }\end{array}$ & $\begin{array}{c}\text { Total } \\
\text { Positive (FP) }\end{array}$ & $\begin{array}{c}\text { False } \\
\text { Negative (FN) }\end{array}$ & False \\
\hline Giemsa (Standard) & 570 & 466 & 104 & - & - \\
Acridine-Giemsa & 570 & 492 & 78 & 18 & 1 \\
Modified QBC & 570 & 494 & 76 & 16 & 0 \\
\hline
\end{tabular}


Table 2: Efficacy of Modified QBC and Concentrated A-G in detection of malarial parasites in human sample using Giemsa staining technique as Gold Standard.

\begin{tabular}{lcc}
\hline Efficacy Index & Modified QBC & Acridine -Giemsa \\
Sensitivity (\%) & 100 & 99.7 \\
\hline Specificity (\%) & 82.50 & 90.7 \\
PPV (\%) & 96.8. & 96.5 \\
NPV (\%) & 100 & 98.7 \\
Positivity & 86.7 & 86.3 \\
Negativity & 13.3 & 13.7 \\
\hline
\end{tabular}

PPV (Positive Predictive Value), NPV (Negative Predictive Value).

\section{DISCUSSION}

This study was carried out to investigate efficacy of modified Quantitative Buffy Coat and mixture of Acridine and Giemsa stains for detection of malaria parasite using Giemsa stained peripheral blood smear as a gold standard. For an effective diagnostic method, the higher the percentage positivity of known cases the more reliable the method. Reverse is usually the case for percentage negativity which is expected to be tending towards zero for good diagnostic techniques. Our findings revealed an insignificant variation in ability of both techniques to detect positive or negative malaria parasite from human blood samples. In the study, the positivity rate for modified QBC was $86.7 \%$ while Acridine-Giemsa staining method recorded it as $86.3 \%$ whereas the negativity rates were $13.3 \%$ and $13.7 \%$ respectively for both methods. The Positive Predictive Value (PPV) also shows insignificant difference with modified QBC and Acridine-Giemsa staining recording $96.8 \%$ and $96.5 \%$ respectively whereas $100 \%$ Negative Predictive Value was documented for Modified QBC method against 98.7 by Acredine-Giemsa staining method in this study.
Although the modified QBC technique recorded maximum sensitivity $(100 \%)$ in the present study, staining with mixture of Acredine and Giemsa depicted a higher specificity (90.7\%)) than modified QBC $(82.5 \%)$. The reason for this scenario could be due to mixture of two dyes used in the former which probably provided a contrast background for the parasite to be clearly identified than when only Acredine stain was used.

Similarly, contrary to the findings from previous studies, $90 \%$ was recorded by Gurung et al. (2010), and $96.22 \%$ by Bhadari et al. (2008), our study recorded $100 \%$ sensitivity with modified technique. The reason for the discrepancy could be due to the difference in the type of capillary tube used. While a thin capillary was used in the present study, the previous one employed a thicker capillary tube.

On the overall, the present findings show a favorable competition between Acridine-Giemsa staining method and Modified QBC technique for detection of malaria parasites. Statistically, there was no significant difference in the efficacy of both techniques when Student T-test was used to analyze the data obtained at $95 \%$ confidence level $(\mathrm{p}=0.7631 ; \mathrm{P}>0.05)$. 


\section{Conclusion}

In conclusion, the study reveals that modified $\mathrm{QBC}$ technique recorded maximum sensitivity of $100 \%$ while concentrated Acredine-Giemsa staining method recorded 99.7\% whereas the later depicted a higher specificity (90.7\%)) than former with $82.5 \%$. Statistical analysis by Students' T-test shows no significant difference in the efficacy of both techniques at 95\% confidence level. Also, both methods gave promising future as good replacements for routine Giemsa staining method in detection of malaria parasites considering their high sensitivity and specificity rates.

\section{COMPETING INTERESTS}

The authors affirm that there is no conflict of interest of any kind among us and that the work has not been previously presented in any form or sent to any journal for publication. All authors of this manuscript have unanimously agreed to publish the work in this journal.

\section{AUTHORS' CONTRIBUTIONS}

The research was conceptualized and designed by AAA and the research proposal was reviewed by IAA and SAN. IAA and SAN conducted the research, collated, organized and analyzed the data while AAA supervised the research methodology and data analysis. The initial draft of the article was jointly written by IAA and SAN while the corrected version was prepared by AAA. Final manuscript was collectively reviewed and approved by all authors

\section{ACKNOWLEDGEMENTS}

We are grateful to Doctor TD Adeniyi in the Department of Medical Laboratory Science University of Medical Sciences, Ondo, Nigeria for taking his time to proofread through the manuscript and his assistance in correcting the grammar of the manuscript. The contributions of Secretary to the Faculty of Allied Health Sciences of the same University Madam Adija Ajifowowe for typing the manuscript of this article is also appreciated.

\section{REFERENCES}

Abba K, Kirkham AJ, Olliaro PL, Deeks JJ, Donegan S, Garner P, Takwoingi Y. 2014. Rapid diagnostic tests for diagnosing uncomplicated nonfalciparum or Plasmodium vivax malaria in endemic countries. Cochrane Database of Systematic Rev., 12: CD011431. DOI: 10.1002/14651858.CD011431.

Abeku TA. 2007. Response to malaria epidemics in Africa. Emerg. Infect. Dis., 13(5): $\quad$ 681-686. DOI: https://dx.doi.org/10.3201\%2Feid1305.0 61333.

Ameri M. 2010. Laboratory diagnosis of malaria in nonhuman primates". Veterinary Clinical Pathol., 39 (1): 519. DOI: https://doi.org/10.1111/j.1939165X.2010.00217.x

Anagu OL, Ikegbunam MN, Unachukwu CK, Uchenna CO, Esimone CO. (2015) Comparison of Microscopic Determination and Rapid Diagnostic Tests (RDTs) in the Detection of Plasmodium Infection. Advances Microbiol., 5(8): 604-609. DOI: 10.4236/aim.2015.58063.

Arnott A, Barry AE, Reeder JC. 2012. Understanding the population genetics of Plasmodium vivax is essential for malaria control and elimination. Malar. J., 11: 14. DOI: 10.1186/1475-2875-1114.

Baird JK. 2009. Malaria zoonoses. Travel Med. Infect. Dis., 7(5): 269-277. DOI: 10.1016/j.tmaid.2009.06.004.

Baird JK. 2013. "Evidence and implications of mortality associated with acute Plasmodium vivax malaria".

Clin. Microbiol. Rev., 26(1): 36-57. DOI: 10.1128/CMR.00074-12.

Bartoloni A, Zammarchi L. 2012. Clinical aspects of uncomplicated and severe malaria. Mediterr. J. Hematol. Infect. Dis., 4(1): e2012026. DOI: 10.4084/MJHID.2012.026. 
Benito A, Roche J, Molina R, Amela C, Alvar J. 1994. Application and evaluation of QBC malaria diagnosis in a holoendemic area. Appl. Parasitol., 35(4): 266-272.

Bhandari PL, Raghuveer CV, Rajeev A, Bhandari PD. 2008. Comparative study of peripheral blood smear, quantitative buffy coat and modified centrifuged blood smear in malaria diagnosis. Indian J. Pathol. Microbiol., 51(1):108-112.

Caraballo H, King K. 2014. Emergency department management of mosquitoborne illness: Malaria, dengue and West Nile virus. Emerg. Med. Pract., 16(5): 125.

Chakrabortya K, Chattopadyayb A, Chakrabarti A, Acharyad T, Dasguptae AK. 2015. A Combined Algorithm for Malaria Detection from Thick Smear Blood Slides. J. Health Med. Informant, 6(179): 2157-7420.

Collins WE. 2012. Plasmodium knowlesi: A malaria parasite of monkeys and humans. Annu. Rev. Entomol., 57: 107121. DOI: 10.1146/annurev-ento121510-133540

Gera M, Chauhan A. 2015. Detection of malaria parasite using different microscopic methods and a comparison between them. IJSR, 4(3): 1635-1638.

Gething PW, Patil AP, Smith DL, Guerra CA, Elyazar IR, Johnston G L, Tatem AJ, Hay SI. 2011. A new world malaria map: Plasmodium falciparum endemicity in 2010". Malar. J., 10(1): 378. DOI: https://doi.org/10.1186/1475-2875-10378.

Gurung B, Bairy I, Jagadishchandra J, Manohar C. 2010. Evaluation of falcivax against quantitative buffy coat (QBC) for the diagnosis of malaria," Int. $J$. Collaborative Res. Internal Med. Public Health, 2(5): 132-140.

Khan SA, Anwar M, Hussain S, Qureshi AH, Ahmad M, Afzal S. 2014. Comparison of Optimal Malarial Test with Light Microscopy for the diagnosis of
Malaria J. Pak. Med. Assoc., 54 (8): 404-407.

Manguin S, Foumane V, Besnard P, Fortes F, Carnevale P. 2017. Malaria over diagnosis and subsequent overconsumption of antimalarial drugs in Angola: Consequences and effects on human health". Acta Trop., 171: 58-63. DOI: 10.1016/j.actatropica.2017.03.022.

Meade MS, Emch M. 2010. Medical Geography (3rd ed.). Guilford Press.

Mehlhorn H. 2008. Disease Control and Methods. In Encyclopedia of Parasitology. Springer: Berlin Heidelberg; 362-366.

Mfopa AL, Mbouna CDJ, Tchokouaha LRY, Tchuente MAT, Kouipou RMT, Fokou PVT, Kemgne EAM, Kamkumo RG, Boyom FF. 2017. In vitro and in vivo antiplasmodial activity of extracts from Polyalthia suaveolens, Uvaria angolensis and Monodora tenuifolia. Int. J. Biol. Chem. Sci., 11(1): 118-130 DOI:http://dx.doi.org/10.4314/ijbcs.v11i 1.10

Mlambo G, Kumar N. 2008. Transgenic rodent Plasmodium berghei parasites as

tools for assessment of functional immunogenicity and optimization of human malaria vaccines". Eukaryotic Cell., $\quad$ 7(11): 1875-1879. DOI: 10.1128/EC.00242-08.

Ngbolua KN, Rafatro H, Rakotoarimanana H, Ratsimamanga US, Mudogo V, Mpiana PT, Tshibangu DST. 2011. Pharmacological screening of some traditionally-used antimalarial plants from the Democratic Republic of Congo compared to their ecological taxonomic equivalence in Madagascar. Int. J. Biol. Chem. Sci., 5(5):1797-1804.

DOI:10.4314/ijbcs.v5i5.3

Olupot-Olupot P, Maitland K. 2013. Management of severe malaria: Results from recent trials. Adv. Exp. Med. Biol., 764: 241-250.

Owusu-Ofori AK, Parry C, Bates I. 2010. Transfusion-transmitted malaria in 
countries where malaria is endemic: A review of the literature from sub-Saharan Africa. Clin. Infect. Dis., 51(10): 11921198. DOI: $10.1086 / 656806$.

Sangare MM, Sina H, Dougnon J, Bayala B, Ategbo JM, Et Dramane KL. 2012. Etude ethnobotanique des plantes hépatotropes et de l'usage traditionnel de Gomphrena celosioides Mart. (Amaranthaceae) au Bénin. Int. J. Biol. Chem. Sci., 6(6):5008-5021. DOI : 10.4314/ijbcs.v6i6.20

Sathpathi S, Mohanty AK, Satpathi P, Mishra SK, Behera PK, Patel G, Dondorp AM. 2014. Comparing Leishman and Giemsa staining for the assessment of peripheral blood smear preparations in a malariaendemic region in India. Malar. J., 13: 512. DOI: 10.1186/1475-2875-13-512.

Shapiro HM, Mandy F. 2007. Cytometry in malaria: moving beyond Giemsa.
Cytometry Part A., 71(9): 643-645. DOI: 10.1002/cyto.a.20453.

Tilley L, Dixon MW, Kirk K. 2011. The Plasmodium falciparum-infected red blood cell. Int. J. Biochem. Cell Biol., 43(6): $\quad 839-842 . \quad$ DOI: 10.1016/j.biocel.2011.03.012.

World Health Organisation. 2010. Guidelines for the treatment of malaria (2nd Ed.). World Health Organization: Geneva. (Accessed $24^{\text {th }}$ January, 2018).

World Health Organization. Regional Office for the Western Pacific. 2016. Malaria microscopy standard operating procedures. Manila: WHO Regional Office for the Western Pacific. http://www.who.int/iris/handle/10665/27 4382 (Accessed 24 $4^{\text {th }}$ January, 2018). 